\title{
Trabecular bone score and bone turnover markers in men with DISH: Data from the Camargo Cohort study
}

\author{
Stefanie F. Pinia ${ }^{\mathrm{a}}$, Giusi A Sgaramella ${ }^{\mathrm{a}}$, Emilio Pariente-Rodrigo ${ }^{\mathrm{b}, \mathrm{d}}$, M. Carmen Ramos-Barrón ${ }^{\mathrm{b}, \mathrm{d}}$, \\ José M. Olmos-Martínez ${ }^{\mathrm{c}, \mathrm{d}}$, José L. Hernández-Hernández ${ }^{\mathrm{c}, \mathrm{d}, *}$ \\ ${ }^{a}$ Home Hospitalization Service, Hospital Marqués de Valdecilla, Cantabria, Spain \\ ${ }^{\mathrm{b}}$ Camargo Health Center, Cantabria, Spain \\ ${ }^{\mathrm{c}}$ Bone Metabolism Unit, Department of Internal Medicine, Hospital Marqués de Valdecilla, Cantabria, Spain \\ ${ }^{\mathrm{d}}$ University of Cantabria, Cantabria, Spain
}

\section{A R T I C L E I N F O}

\section{Keywords:}

Diffuse idiopathic skeletal hyperostosis

Trabecular bone score

Bone turnover markers

Bone metabolic deseases

\begin{abstract}
A B S T R A C T
Objective: Diffuse idiopathic skeletal hyperostosis (DISH) has been associated with an increased risk of vertebral fracture. To date, no studies have investigated the relationship between DISH and bone microstructure assessed by the trabecular bone score (TBS).

Methods: Cross-sectional study, nested in a prospective population-based cohort. All men (968) aged $\geq 50$ years were included. Clinical covariates, DISH, TBS, serum bone turnover markers and bone mineral density (BMD) were analyzed.

Results: Mean age of participants was $65 \pm 9$ years. 207 (21.6\%) had DISH. DISH subjects were older, had higher body mass index (BMI) and abdominal perimeter, lower glomerular filtration rate (GFR), and higher prevalence of metabolic syndrome (MetS) than non-DISH (NDISH) subjects. Bone mineral density at the lumbar spine (LS-BMD) was significantly higher in the DISH group. TBS values were 1.317 [1.303-1.331] for DISH and 1.334 [1.327-1.341] for NDISH subjects, after adjusting by age, BMI, abdominal perimeter, arterial hypertension, diabetes mellitus, MetS, GFR, serum alkaline phosphatase (ALP), LS and femoral neck BMD $(p=0.03)$. Serum ALP levels were higher in DISH subjects, showing an inverse correlation with TBS that remained significant after adjusting by age and BMI.

Conclusions: TBS values were significantly lower in men with DISH irrespective of age, BMI and BMD, suggesting that the presence of DISH might be related to a worse trabecular microstructure.
\end{abstract}

(c) 2020 Elsevier Inc. All rights reserved.

\section{Introduction}

Diffuse idiopathic skeletal hyperostosis (DISH) is a non-inflammatory rheumatic disorder characterized by ossification of ligaments, tendons and joint capsules, first described by Forestier and RotésQuerol in 1950 [1,2]. It can affect numerous locations, but the involvement of the anterior vertebral ligament of the thoracic spine is the most characteristic manifestation of the disease [3,4]. DISH is more frequent in older men and its pathogenesis remains unknown, although genetic, mechanical and metabolic factors, mainly abdominal obesity, have been involved [4,5]. Furthermore, growth factors, bone morphogenetic proteins (BMP) or adipokines, have also been implicated in DISH pathogenesis, since they would act on the fibroblasts, chondrocytes and collagen fibers of the entheses promoting bone neoformation [6].

\footnotetext{
* Corresponding author at: Bone Metabolism Unit. Department of Internal Medicine, Hospital Marqués de Valdecilla-IDIVAL, University of Cantabria, Santander, Spain

E-mail address: hernandezjluis@gmail.com (J.L. Hernández-Hernández).
}

DISH is usually an asymptomatic condition, although joint pain, limited axial mobility, dysphagia, airway obstruction, as well as increased susceptibility to vertebral fractures, have been reported [7-9]. These fractures are often associated with neurological complications and higher mortality rate [10]. The role of bone mineral density (BMD) in the development of vertebral fractures in subjects with DISH represents a matter of debate [11]. High BMD values have been reported in these patients, both in the axial [12] and in the appendicular skeleton [13-15], which would paradoxically imply a lower risk of fracture. In fact, it has been pointed out that the bone in DISH is denser but at the same time more fragile [7]. However, some other authors have questioned this observation, suggesting that high BMD values measured by dual-energy x-ray absorptiometry (DXA) may be overestimated, due to the effect of anterior vertebral ligament ossification [11].

Nevertheless, there are other factors that can contribute to the risk of fracture, independently of BMD, such as the rate of bone turnover, the degree of matrix mineralization, the geometry (dimensions, cortical thickness) or the integrity of the trabecular structure, all 
dynamic processes that, together with BMD, determine bone strength [16,17].

Data on bone biomarkers in patients with DISH are scarce, and increased levels of osteocalcin, secreted frizzled-related proteins and sclerostin and decreased levels of dickkopf-related protein 1 (DKK-1) have been reported $[18,19]$.

Trabecular bone score (TBS) is an image technique developed to indirectly evaluate the state of the trabecular microarchitecture based on the information provided by the standard DXA [20]. It consists of a texture parameter that evaluates pixel gray-level variations in the projected lumbar spine DXA image. Thus, TBS may be considered as an overall index of bone quality and low values have been associated with a worse bone structure and a higher risk of fracture $[20,21]$. The usefulness of TBS in fracture risk assessment or for therapeutic recommendations in patients with osteoporosis has been addressed in a recent Position Development Conference by The International Society for Clinical Densitometry [22].

To our knowledge, TBS values in patients with DISH have not been reported to date.

Based on these considerations, our aim has been to assess the TBS values in a population-based cohort of men aged 50 years or older, with and without DISH. Given the paucity of data, a second objective has been to compare the serum levels of markers of bone formation and bone resorption in DISH and non-DISH (NDISH) subjects.

\section{Patients and methods}

\section{Population and sample}

The study population included all the men aged $\geq 50$ years taking part in a prospective population-based cohort, the Camargo Cohort, whose full details have been previously published [23]. Briefly, the Camargo Cohort was set up in 2006 to assess the prevalence and incidence of bone metabolic diseases in postmenopausal women and men aged $\geq 50$ years, who attended two health care centers in Cantabria, Spain.

At baseline, patients were asked to complete a questionnaire on bone metabolism and general diseases, current or past medication use and risk factors for osteoporosis and fragility fractures. Moreover, blood samples were collected and all the participants underwent lateral thoracic and lumbar spine radiographs and a DXA exam. The Camargo Cohort study was approved by the Clinical Research Ethics Committee of Cantabria (Internal Code 2014.155). All participants gave written informed consent.

Participants whose baseline assessment revealed the presence of diseases or treatments known to affect bone metabolism, such as osteoporosis, primary hyperparathyroidism, hyperthyroidism, serum creatinine $>1.7 \mathrm{mg} / \mathrm{dl}(151 \mu \mathrm{mol} / \mathrm{L})$, or use of bisphosphonates, estrogen, raloxifene, strontium ranelate, teriparatide, L-thyroxin, anticonvulsants or glucocorticoids in the previous year, were excluded. We also excluded patients with previous diagnosis of ankylosing spondylitis or chronic liver disease.

\section{Clinical variables}

Weight (in $\mathrm{kg}$ ), height (in meters) and abdominal perimeter (in $\mathrm{cm}$ ) were obtained with the subjects wearing underwear and without shoes. Body mass index (BMI) was measured in $\mathrm{kg} / \mathrm{m}^{2}$, considering obesity when BMI $\geq 30 \mathrm{~kg} / \mathrm{m}^{2}$. Physical activity was categorized as sedentary (sitting in a chair most of the time, short walks outside the house), light (shopping, domestic work) or moderate-intense (daily -or most days- exercise or intense work).

Smoking was defined as non-smokers or smokers (current smokers and ex-smokers). Alcohol intake was defined as a daily consumption greater than $20 \mathrm{~g}$ [24].
Blood samples were obtained from an antecubital vein in the morning after a requested 12-hour overnight fast. Serum concentrations of calcium, phosphorus, albumin and total alkaline phosphatase (ALP) were obtained by automated methods in an ADVIA ${ }^{\circledR} 2400$ Chemistry System autoanalyzer (Siemens, Germany). Serum concentrations of 25-hydroxyvitamin D (25-OHD), intact parathyroid hormone (iPTH), amino-terminal pro-peptide of type 1 collagen (PINP) and C-terminal telopeptide of type 1 collagen (CTX) were determined by an automated method of electrochemiluminescence (Elecsys ${ }^{\circledR}$ 2010, Roche Diagnostics, GmbH, Mannheim, Germany). The detection limits for iPTH, P1NP and CTX were $6 \mathrm{pg} / \mathrm{ml}, 5 \mathrm{ng} / \mathrm{ml}$ and $0.01 \mathrm{ng} / \mathrm{ml}$, and the normality ranges were $15-65 \mathrm{pg} / \mathrm{ml}, 15-78 \mathrm{ng} / \mathrm{ml}$ and $0.069-0.760 \mathrm{ng} / \mathrm{ml}$, respectively. The glomerular filtration rate (GFR) was estimated according to the CKD-EPI formula [25] and expressed in $\mathrm{ml} / \mathrm{min} / 1.73 \mathrm{~m}^{2}$. Metabolic syndrome (MetS) was defined according to the NCEP-ATPIII criteria [26].

BMD was measured by DXA, with a Hologic ${ }^{\circledR}$ QDR-4500 device, at the lumbar spine (LS-BMD), femoral neck (FN-BMD) and total hip (TH-BMD). In-vivo precision was $0.4-1.5 \%$ at different locations, and the results were expressed in $\mathrm{gr} / \mathrm{cm}^{2}$. All measurements were made by the same operator. The measurement of the TBS has been carried out from the images of the DXA in LS (L1-L4) stored in the densitometer memory, with the TBS iNsight software (TBS iNsight ${ }^{\circledR}$ v2.1, Medimaps, Mérignac, France) installed in the densitometer.

Two independent trained researchers, blinded to clinical data, evaluated DISH and vertebral fractures. DISH was diagnosed according to the Resnick and Niwayama criteria [27]: ossifications affecting the anterior longitudinal vertebral ligament of at least 4 contiguous vertebral bodies, a relative preservation of the intervertebral disk space in the affected segment without signs of degenerative disk changes, and the absence of apophyseal joint degeneration or sacroiliac inflammatory changes. The grade of vertebral fracture was assessed by the semiquantitative method of Genant [28].

\section{Statistical analysis}

Quantitative variables were expressed as mean \pm standard deviation (SD) or median [interquartile range], and categorical variables, in percentage. Student-t-test, Mann-Whitney U test, median test and ANOVA, were used to compare quantitative variables, and Pearson's chi-squared test in the case of categorical variables. The relationships between variables were initially analyzed through bivariate correlations using Pearson or Spearman coefficients and then, univariable linear regression models. The risk was expressed as prevalence odds ratio (OR) with $95 \%$ confidence interval $(95 \% \mathrm{CI})$. A general linear regression model was built to assess the relationship between DISH and TBS, including the covariates that showed significant differences between DISH and NDISH groups. Bonferroni adjustment for multiple testing was also carried out. A p-value $<0.05$ was considered statistically significant in all the analyses.

\section{Results}

A total of 1113 men aged $\geq 50$ years were initially recruited. Of them, 145 were excluded because of incomplete data or having diseases or receiving treatments that affect bone metabolism. Thus, 968 participants (mean age, $65 \pm 9$ years; range, 50-92 years) were finally included in the study, and 207 of them (21.6\%) were diagnosed with DISH.

DISH was associated with age $(r=0.202 ; p<0.0001)$ and BMI $(r=0.111 ; p=0.001)$. Thus, increasing prevalence of DISH was observed in the elderly ( $15.6 \%$ in subjects $<65$ years vs. $29.2 \%$ in those $\geq 65$ years; $p<0.0001$ ) and in obese participants (17.3\% in subjects with BMI $<30$ vs. $28.8 \%$ in those with BMI $\geq 30 ; p<0.0001)$.

The main epidemiological characteristics of participants with and without DISH are summarized in Table 1. DISH subjects were older, 
Table 1

Baseline clinical characteristics according to DISH status.

\begin{tabular}{|c|c|c|c|}
\hline & DISH $(N=207)$ & $\operatorname{NDISH}(N=761)$ & $P$ \\
\hline Age, yrs. & $67(15)$ & $62(13)$ & 0.0001 \\
\hline Body mass index, $\mathrm{Kg} / \mathrm{m}^{2}$ & $29.9(4.4)$ & $28.7(4.1)$ & 0.0001 \\
\hline Abdominal perimeter, $\mathrm{cm}$ & $105(12.7)$ & $101(12)$ & 0.0001 \\
\hline Obesity, $n(\%)$ & $103(49.7)$ & $257(33.7)$ & 0.0001 \\
\hline Diabetes mellitus, $n(\%)$ & $46(22.2)$ & $142(18.6)$ & 0.27 \\
\hline Arterial hypertension, $n(\%)$ & $118(57)$ & $356(46.8)$ & 0.01 \\
\hline Dyslipidemia; $n(\%)$ & $75(36.2)$ & $260(34.1)$ & 0.58 \\
\hline GFR, $\mathrm{ml} / \mathrm{min} / 1.73 \mathrm{~m}^{2}$ & $74.4(21.8)$ & $78(23)$ & 0.01 \\
\hline Metabolic syndrome; $n(\%)$ & $99(47.8)$ & $238(31.2)$ & 0.0001 \\
\hline
\end{tabular}

NDISH: Non-DISH. GFR: glomerular filtration rate

Quantitative variables are expressed in median (interquartile range).

had higher BMI and abdominal perimeter, lower GFR, and higher prevalence of MetS than NDISH participants had. Besides, LS-BMD was significantly higher in DISH subjects compared to the NDISH group (Table 2), also with increased values in the oldest men: 1.044 vs. $0.988 \mathrm{~g} / \mathrm{cm}^{2}$ in the group $<65$ years $(p=0.002)$, and 1.073 vs. $0.986 \mathrm{~g} / \mathrm{cm}^{2}$ in those $\geq 65$ years $(p=0.006)$.

TBS was inversely correlated to age $(r=-0.179 ; p<0.0001)$ and BMI $(r=-0.467 ; p<0.0001)$. TBS median values were 1.328 [1.222-1.405] in the DISH group vs. 1.352 [1.255-1.433] in NDISH subjects $(p=0.02)$ (Table 2). The presence of DISH was associated with a lower TBS: $57.1 \%$ of the DISH subjects had a TBS below the median of the whole sample (1.346), compared to $48.7 \%$ of the NDISH subjects, with an unadjusted OR value of 1.40 (95\% CI 1.03-1.92); $p=0.03$. After adjusting by age, BMI, abdominal perimeter, arterial hypertension, diabetes mellitus, MetS, GFR, ALP, LS-BMD and FNBMD, TBS values were 1.317 [1.303-1.331] and 1.334 [1.327-1.341] in DISH and NDISH groups, respectively $(p=0.03)$.

As the TBS shows better performance when BMI ranges from 15 to $35 \mathrm{~kg} / \mathrm{m}^{2}$ [29], this issue was addressed by previously excluding subjects with BMI $>35 \mathrm{~kg} / \mathrm{m}^{2}$ in the analysis. However, the results did not virtually change when including these subjects (adjusted TBS value of 1.325 [1.314-1.336] in DISH vs 1.339 [1.331-1.347] in NDISH participants; $p=0.02$ )

Regarding bone biomarkers, subjects with DISH had higher serum ALP levels than NDISH individuals $(p=0.049)$, while PINP and CTX levels were similar in both groups. Serum ALP levels showed an inverse correlation with TBS $(r=-0.104 ; p=0.001)$ that remained

Table 2

Bone metabolism parameters according to DISH status.

\begin{tabular}{|c|c|c|c|}
\hline & $\operatorname{DISH}(N=207)$ & $\operatorname{NDISH}(N=761)$ & $P$ \\
\hline $\begin{array}{l}\text { Trabecular bone score (TBS), } \\
\text { unitless }\end{array}$ & $1.328(0.2)$ & $1.352(0.1)$ & 0.02 \\
\hline Vertebral Fracture; $n(\%)$ & $43(20.7)$ & $151(19.8)$ & 0.76 \\
\hline $\begin{array}{l}\text { History of fracture }>40 \text { years } \\
\text { old; } n(\%)\end{array}$ & $31(15)$ & $122(16)$ & 0.71 \\
\hline Albumin, $g / d l$ & $4.4(0.3)$ & $4.5(0.5)$ & 0.60 \\
\hline Calcium, $m g / d l$ & $9.5(0.5)$ & $9.5(0.6)$ & 0.65 \\
\hline Phosphate, $m g / d l$ & $3(0.5)$ & $3(0.7)$ & 0.39 \\
\hline $\mathrm{iPTH}, p g / m l$ & $51.5(24.6)$ & $51.8(24)$ & 0.37 \\
\hline $25(\mathrm{OH}) \mathrm{D}, n g / m l$ & $22(10.8)$ & $22(11)$ & 0.42 \\
\hline Alkaline phosphatase, $U / L$ & $67(23)$ & $64(22)$ & 0.049 \\
\hline $\mathrm{P} 1 \mathrm{NP}, \mathrm{ng} / \mathrm{ml}$ & $35.5(20.5)$ & $34(18.7)$ & 0.32 \\
\hline $\mathrm{CTX}, n g / m l$ & $0.2(0.2)$ & $0.2(0.2)$ & 0.50 \\
\hline LS BMD, $\mathrm{g} / \mathrm{cm}^{2}$ & $1.05(0.2)$ & $0.98(0.2)$ & 0.0001 \\
\hline FN BMD, $\mathrm{g} / \mathrm{cm}^{2}$ & $0.82(0.2)$ & $0.80(0.1)$ & 0.04 \\
\hline TH BMD, $\mathrm{g} / \mathrm{cm}^{2}$ & $0.98(0.1)$ & $0.97(0.1)$ & 0.11 \\
\hline
\end{tabular}

NDISH: Non-DISH. 25(OH)D: 25-hydroxyvitamin D; iPTH: intact parathyroid hormone; P1NP: amino-terminal pro-peptide of type 1 collagen; CTX: C-terminal telopeptide of type 1 collagen. BMD: bone mineral density; LS; lumbar spine; FN: femoral neck; TH: total hip.

Quantitative variables are expressed in median (interquartile range), with the exception of total hip BMD, expressed as mean (standard deviation). significant after adjusting by age and BMI. No correlation was observed between TBS values and serum PINP or CTX levels.

\section{Discussion}

To our knowledge, this is the first study that assesses the TBS values in DISH subjects. We have shown that there is an inverse relationship between DISH and TBS, independently of age, BMI, BMD, and other covariates. This finding might represent a biologically plausible explanation, among others, of the propensity to vertebral fractures independently of BMD found in patients with DISH.

Despite the great variability, the observed prevalence of DISH of $21.6 \%$ in men $>50$ years is in line with the data reported in studies based on plain radiographs [30]. The clinical characteristics of DISH patients observed in our study were also similar to those previously published, specifically the higher average age and the higher prevalence of obesity [5]. Likewise, age has also been inversely associated with TBS values [20], as observed in our study. Besides, obesity was significantly more prevalent in our DISH group, and BMI and TBS were inversely correlated. In this sense, there is a well-known relationship between obesity and DISH [4,5]. Serum adipokines with effect on the regulation of bone metabolism (mainly leptin and adiponectin) have been suggested as a potential pathophysiological link [31-33]. Furthermore, the metabolic environment of obesity (insulin resistance and inflammation) may be associated with impaired bone health in obese individuals [34]. With regard to TBS values in obese subjects, a recent report has found that obesity was associated with a low TBS in men, irrespective of BMD [35].

Concerning bone biomarkers in patients with DISH, there is not yet a clearly established pattern. We have evaluated two serum markers of bone formation, ALP and PINP, and a marker of bone resorption, CTX. ALP values were significantly higher in the DISH group and have shown an inverse correlation with TBS. In the same line, increased ALP levels have been reported in DISH subjects [36]. Moreover, experimental studies seem to support this clinical observation, since an increase in ALP activity has been observed in ligament cells cultures from patients with DISH, reflecting the transformation of these cells into osteoblasts [37]. Some studies have reported that the changes of the total ALP with age are essentially due to the bone isoenzymes, and in fact, elevated ALP in postmenopausal women has been reported to be mainly caused by high bone turnover [38]. Serum osteocalcin has also been reported to be increased in patients with DISH [18,39]. The higher levels of ALP and the inverse correlation with TBS in DISH subjects might reflect the sensitivity of trabecular bone to an increased bone turnover [40]. Nevertheless, serum PINP levels were similar in DISH and NDISH subjects, which is in line with a recent study on 49 men that underwent surgery for ossification of the posterior longitudinal ligament in cervical spine (OPLL). The authors observed that PINP levels were not significantly different in subjects with OPLL associated with DISH, compared to those with cervical spondylosis [41].

Regarding to bone resorption markers, we have observed no differences in serum CTX levels in subjects with or without DISH. In this sense, serum levels of tartrate-resistant acid phosphatase 5b (TRAP$5 \mathrm{~b})$, another biomarker of bone resorption, have been assessed in a recent report, but no differences between DISH and NDISH subjects were found [41]. With regard to the physiologic regulators of bone turnover, DISH has been related to reduced DKK-1 levels, a protein that inhibits osteogenesis induced by the $\mathrm{Wnt} / \beta$-catenin pathway $[18,19]$.

This pattern of high values of markers of bone formation -ALP, osteocalcin- as well as a decrease in DKK-1 levels would be consistent with the anabolic phenotype of DISH [19]. Although the idea of defining DISH as a bone-forming disorder is intuitively attractive, our study has shown that men with DISH had a higher level of ALP but also a lower TBS. These results might support the bone production/ 
loss continuum ("bone-former, bone-loser") of DISH, as Kuperus et al. [42] have recently suggested.

Our study presents the limitations inherent to its transversal design, which allows investigating for association but not for directionality or causality. Another weakness is the lack of availability of serum osteocalcin levels. Nevertheless, its main strength is that it provides an analysis of the TBS values in DISH on a wide and wellcharacterized prospective cohort of men over 50 years, not previously performed, to our knowledge.

\section{Conclusion}

In conclusion, TBS values were significantly lower in men diagnosed with DISH irrespective of age, BMI, and BMD. Our results might suggest that in men $>50$ years, the process of ligamentous ossification characteristic of DISH might be related to a worse trabecular microstructure. Besides, serum ALP levels were higher in DISH individuals supporting the idea, together with the TBS results, that DISH could be a bone production/loss continuum process and not a classic bone-forming disorder. Future longitudinal studies are needed to deep insight into the usefulness of TBS for assessing the risk of fracture in these patients.

\section{Declaration of Competing Interest}

None.

\section{Funding}

The study has been funded by grants from the Instituto de Salud Carlos III (PI18/00762), Ministerio de Ciencia, Innovación y Universidades, Spain, that included FEDER funds from the EU.

\section{References}

[1] Resnick D, Shapiro RF, Wiesner KB, Niwayama G, Utsinger PD, Shaul SR. Diffuse idiopathic skeletal hyperostosis (DISH). ankylosing hyperostosis of Forestier and Rotes-Querol. Semin Arthritis Rheum 1978;7:153-87.

[2] Forestier J, Rotés-Querol J. Senile ankylosing hyperostosis of the spine. Ann Rheum Dis 1950;9:321-30.

[3] Mader R, Sarzi-Puttini P, Atzeni F, Olivieri I, Pappone N, Verlaan JJ, et al. Extraspinal manifestations of diffuse idiopathic skeletal hyperostosis. Rheumatol 2009;48: $1478-81$.

[4] Mader R, Verlaan JJ, Buskila D. Diffuse idiopathic skeletal hyperostosis: clinical features and pathogenic mechanisms. Nat Rev Rheumatol 2013:9:741-50.

[5] Pillai S, Littlejohn G. Metabolic factors in diffuse idiopathic skeletal hyperostosis: a review of clinical data. Open Rheumatol J 2014;8:116-28.

[6] Li H, Jiang LS, Dai LY. Hormones and growth factors in the pathogenesis of spinal ligament ossification. Eur Spine J 2007;16:1075-84.

[7] Diederichs G, Engelken F, Marshall LM, Peters K, Black DM, Issever AS, et al. Diffuse idiopathic skeletal hyperostosis (DISH): relation to vertebral fractures and bone density. Osteoporos Int 2011;22:1789-97.

[8] Westerveld LA, van Bemmel JC, Dhert WJA, Oner FC, Verlaan JJ. Clinical outcome after traumatic spinal fractures in patients with ankylosing spinal disorders compared with control patients. Spine J 2014;14:729-40.

[9] Caron T, Bransford R, Nguyen Q, Agel J, Chapman J, Bellabarba C. Spine fractures in patients with ankylosing spinal disorders. Spine (Phila Pa 1976) 2010;35:E458-64.

[10] Westerveld LA, Verlaan JJ, Oner FC. Spinal fractures in patients with ankylosing spinal disorders: a systematic review of the literature on treatment, neurological status and complications. Eur Spine J 2009;18:145-56.

[11] Westerveld LA, Verlaan JJ, Lam MG, Scolten WP, Bleys RL, Dhert WJ, et al. The influence of diffuse idiopathic skeletal hyperostosis on bone mineral density measurements of the spine. Rheumatol 2009:48:1133-6.

[12] Sahin G, Polat G, Bagis S, Milcan A, Erdogan C. Study of axial bone mineral density in postmenopausal women with diffuse idiopathic skeletal hyperostosis related to type 2 diabetes mellitus. J Women's Health (Larchmt) 2002;11:801-4

[13] Di Franco M, Mauceri MT, Sili-Scavalli A, Iagnocco A, Ciocci A. Study of peripheral bone mineral density in patients with diffuse idiopathic skeletal hyperostosis. Clin Rheumatol 2000;19:188-92.

[14] Littlejohn JO, Urowitz MB, Smythe HA, Keystone EC. Radiographic features of the hand in diffuse idiopathic skeletal hyperostosis (DISH). Diagn Radiol 1981;140: $623-9$.
[15] Huang GS, Park YH, Taylor JAM, et al. Hyperostosis of the ribs: association with vertebral ossification. J Rheumatol 1993:29:2073-6.

[16] Albrand G, Munoz F, Sornay-Rendu E, DuBoeuf F, Delmas PD. Independent predictors of all osteoporosis-related fractures in healthy postmenopausal women: the OFELY study. Bone 2003;32:78-85.

[17] Rubin CD. Emerging concepts in osteoporosis and bone strength. Curr Med Res Opin 2005;21:1049-56

[18] Niu CC, Lin SS, Yuan LJ, Chen LH, Yang CY, Chung AN, et al. Correlation of blood bone turnover biomarkers and WNT signaling antagonists with AS, DISH, OPLL, and OYL. BMC Musculoskelet Disord 2017:18:61.

[19] Senolt L, Hulejova H, Krystufkova O, Forejtova S, Andrés-Cerezo L, Gatterova J et al. Low circulating Dickkopf-1 and its link with severity of spinal involvement in diffuse idiopathic skeletal hyperostosis. Ann Rheum Dis 2012;71:71-4.

[20] Silva BC, Leslie WD, Resch H, Lamy O, Lesnyak O, Binkley N, et al. Trabecular bone score: a noninvasive analytical method based upon the dxa image. J Bone Mine Res 2014;29:518-30.

[21] Martineau P, Leslie WD. Trabecular bone score (TBS): method and applications. Bone 2017;104:66-72.

[22] Shepherd JA, Schousboe JT, Broy SB, Engelke K, Leslie WD. Executive summary of the 2015 ISCD position development conference on advanced measures from DXA and QCT: fracture prediction beyond BMD. J Clin Densitom 2015;18:274-86

[23] Olmos JM, Hernández JL, Martínez J, Pariente E, Llorca J, González-Macías J. Bone turnover markers in spanish adult men. The Camargo Cohort study Clin Chim Acta 2010;411:1511-5.

[24] Becker U, Deis A, Sørensen TI, Grønbaek M, Borch-Johnsen K, Müller CF, et al. Prediction of risk of liver disease by alcohol intake, sex, and age: a prospective population study. Hepatol 1996;23:1025-9.

[25] Levey AS, Stevens LA, Schmid CH, Zhang YL, 3rd CAF, Feldman HI, et al. CKD-EPI (Chronic kidney disease epidemiology collaboration). A new equation to estimate glomerular filtration rate. Ann Intern Med 2009;150:604-12.

[26] Alberti KG, Zimmet P, Shaw J. Metabolic syndrome - A new world-wide definition. A Consensus Statement from the International Diabetes Federation. Diabet Med 2006;23:469-80

[27] Resnick D, Niwayama G. Diagnosis of bone and joint disorders. Philadelphia. 2nd ed. WB Saunders; 1988. p. 1563-615

[28] Genant HK, Wu CY, Van Kuijk MC. Vertebral fracture assessment using a semiquantitative technique. J Bone Miner Res 1993:8:1137-48.

[29] Silva BC, Broy SB, Boutroy S, Schousboe JT, Shepherd JA, Leslie WD. Fracture risk prediction by non-BMD DXA measures: the 2015 ISCD official positions part 2 trabecular bone score. J Clin Densitom 2015;18:309-30.

[30] Weinfeld RM, Olson PN, Maki DD, Griffiths HJ. The prevalence of diffuse idiopathic skeletal hyperostosis (DISH) in two large American Midwest metropolitan hospital populations. Skeletal Radiol 1997;26:222-5.

[31] Tenti S, Palmitesta P, Giordano N, Galeazzi M, Fioravanti A. Increased serum leptin and visfatin levels in patients with diffuse idiopathic skeletal hyperostosis: a comparative study. Scand J Rheumatol 2017;46:156-8.

[32] Ikeda Y Nakajima A, Aiba A, Koda M, Okawa A, Takahashi K et al. Association between serum leptin and bone metabolic markers and the development of heterotopic ossification of the spinal ligament in female patients with ossification of the posterior longitudinal ligament. Eur Spine J 2011;20:1450-8.

[33] Mader R, Novofastovski I, Schwartz N, Rosner E. Serum adiponectin levels in patients with diffuse idiopathic skeletal hyperostosis (DISH). Clin Rheumatol 2018;37:2839-45.

34] Gower BA, Casazza K. Divergent effects of obesity on bone health. J Clin Densitom 2013;16:450-4.

[35] Romagnoli E, Lubrano C, Carnevale V, Costantini D, Nieddu L, Morano S, et al. Assessment of trabecular bone score (TBS) in overweight/obese men: effect of metabolic and anthropometric factors. Endocrine 2016:54:342-7.

[36] Miyazawa N, Akiyama I. Diffuse idiopathic skeletal hyperostosis associated with risk factors for stroke. A case-control study. Spine 2006;31:I225-9.

37] Kosaka T, Imakiire A, Mizuno F, Yamamoto K. Activation of nuclear facto kappaB at the onset of ossification of the spinal ligaments. J Orthop Sci 2000;5:572-8

[38] Mukaiyama K, Kamimura M, Uchiyama S, Ikegami S, Nakamura Y, Kato H. Elevation of serum alkaline phosphatase (ALP) level in postmenopausal women is caused by high bone turnover. Aging Clin Exp Res 2015;27:413-8.

[39] Popova MG, Andreev S, Pavlov P, Ilev D, Popova S. Study of serum levels of osteocalcin (s-OC) on patients with diffuse idiopathic skeletal hyperostosis (DISH) and ankylosing spondylitis (AS). In: Program of the Annual Meeting of the American College of Rheumatology (ACR/ARHP), S. Diego; 2013. (Abstract number 1831) Available at https://acrabstracts.org/abstract/study-of-serum-levels-of-osteocalcin-s-oc-on-patients-with-diffuse-idiopathic-skeletal-hyperostosis-dish-andankylosing-spondilitis-as/.

[40] Kreider JN, Goldstein SA. Trabecular bone mechanical properties in patients with fragility fractures. Clin Orthop Relat Res 2009;467:1955-63.

[41] Horie S, Sawaji Y, Endo K, Suzuki H, Matsuoka Y, Nishimura H, et al. Factors associated with bone metabolism in patients with cervical ossification of the posterior longitudinal ligament accompanied with diffuse idiopathic skeletal hyperostosis. SICOT J 2018;4:7.

[42] Kuperus JS, Samsour L, Buckens CF, Oner FC, de Jong PA, Verlaan JJ. Bone minera density changes over time in diffuse idiopathic skeletal hyperostosis of the thoracic spine. Bone 2018;112:90-6. 